\title{
Real-Time Forecasting with a Large, Mixed Frequency, Bayesian VAR
}

\author{
Michael W. McCracken, Michael T. Owyang \\ Federal Reserve Bank of Saint Louis
}

\author{
Tatevik Sekhposyan \\ Texas A\&M University
}

\section{Society of Economic Measurement's Second Conference} June 24, 2015 


\section{Problem}

Key issues to forecasting in practice

- many variables released

- at varying frequencies

- with publication lags

- at different times during the quarter 


\section{Problem}

Key issues to forecasting in practice

- many variables released

- at varying frequencies

- with publication lags

- at different times during the quarter

How to postulate a model that combines the information in the data in the best way given the restrictions? 


\section{Problem}

Key issues to forecasting in practice

- many variables released

- at varying frequencies

- with publication lags

- at different times during the quarter

How to postulate a model that combines the information in the data in the best way given the restrictions?

Yet, in addition, allows for a general framework, that enables us

- to construct forecasts conditional on "appropriate monetary policy" (i.e. condition on the path of the funds rate)

- to construct impulse response functions and density forecasts

- to explain "why" the forecasts changed since ... 


\section{Problem: it is Hard!}

From econometric point of view

- parsimonious models usually perform better: tradeoff between over-fitting and out-of-sample performance

- included variables should be "worth" the estimation risk 


\section{Problem: it is Hard!}

From econometric point of view

- parsimonious models usually perform better: tradeoff between over-fitting and out-of-sample performance

- included variables should be "worth" the estimation risk

Resolutions

- autoregressive models

- VARs in common low (quarterly) frequency

- factor models: Stock \& Watson (2002), Giannone, Reichlin \& Small (2008), Aruoba, Diebold \& Scotti (2009), etc.

- MIDAS models: Ghysels, Santa Clara \& Volkanov (2004), etc.

- VARs: Bańbura, Giannone \& Reichlin (2010), Schorfheide \& Song (in press), Foroni, Guérin \& Marcellino (in press), etc. 


\section{Our Resolution}

Take the VAR route

- Define a VAR that allows for monthly and quarterly data

- Monthly variables are treated at a quarterly frequency blocking, stacking (Chen, Anderson, Deistler, Filler, 2011)

- Impose certain restrictions on the VAR consistent with the timing of data releases 


\section{Our Resolution}

Take the VAR route

- Define a VAR that allows for monthly and quarterly data

- Monthly variables are treated at a quarterly frequency blocking, stacking (Chen, Anderson, Deistler, Filler, 2011)

- Impose certain restrictions on the VAR consistent with the timing of data releases

Similar to Ghysels (in press), but in out-of-sample, large VAR and used in real-time environment while relying on shrinkage 


\section{What is Blocking? An Example 1}

- Suppose 2 series: quarterly GDP growth $\left\{y_{t}\right\}$ and monthly UR $\left\{x_{t-2 / 3}, x_{t-1 / 3}, x_{t}\right\}$ 


\section{What is Blocking? An Example 1}

- Suppose 2 series: quarterly GDP growth $\left\{y_{t}\right\}$ and monthly UR $\left\{x_{t-2 / 3}, x_{t-1 / 3}, x_{t}\right\}$

- Let $W_{t}=\left[x_{t-2 / 3}, x_{t-1 / 3}, x_{t}, y_{t}\right]^{\prime}$ 


\section{What is Blocking? An Example 1}

- Suppose 2 series: quarterly GDP growth $\left\{y_{t}\right\}$ and monthly UR $\left\{x_{t-2 / 3}, x_{t-1 / 3}, x_{t}\right\}$

- Let $W_{t}=\left[x_{t-2 / 3}, x_{t-1 / 3}, x_{t}, y_{t}\right]^{\prime}$

- Specify the VAR

$$
A_{0} W_{t}=C+\sum_{\ell=1}^{4} A_{\ell} W_{t-\ell}+e_{t}
$$

- $E\left(e_{t} \mid W_{1}, \ldots, W_{t-1}\right)=0$

- $E\left(e_{t} e_{t}^{\prime} \mid W_{1}, \ldots, W_{t-1}\right)=I$

- $A_{\ell}$ is unrestricted

- consider restrictions on $A_{0}$ motivated by the temporal ordering 


\section{What is Blocking? An Example 1}

- Suppose 2 series: quarterly GDP growth $\left\{y_{t}\right\}$ and monthly UR $\left\{x_{t-2 / 3}, x_{t-1 / 3}, x_{t}\right\}$

- Let $W_{t}=\left[x_{t-2 / 3}, x_{t-1 / 3}, x_{t}, y_{t}\right]^{\prime}$

- Specify the VAR

$$
A_{0} W_{t}=C+\sum_{\ell=1}^{4} A_{\ell} W_{t-\ell}+e_{t}
$$

- $E\left(e_{t} \mid W_{1}, \ldots, W_{t-1}\right)=0$

- $E\left(e_{t} e_{t}^{\prime} \mid W_{1}, \ldots, W_{t-1}\right)=I$

- $A_{\ell}$ is unrestricted

- consider restrictions on $A_{0}$ motivated by the temporal ordering

- At time $t$ UR is released before GDP (1st week vs. last week)

$$
A_{0}=\left(\begin{array}{llll}
a_{11} & 0 & 0 & 0 \\
a_{21} & a_{22} & 0 & 0 \\
a_{31} & a_{32} & a_{33} & 0 \\
a_{41} & a_{42} & a_{43} & a_{44}
\end{array}\right)
$$




\section{What is Blocking? An Example 2}

- Suppose 3 series: quarterly GDP growth $\left\{y_{t}\right\}$, monthly UR $\left\{x_{t-2 / 3}, x_{t-1 / 3}, x_{t}\right\}$ and monthly $\operatorname{EMP}\left\{z_{t-2 / 3}, z_{t-1 / 3}, z_{t}\right\}$ 


\section{What is Blocking? An Example 2}

- Suppose 3 series: quarterly GDP growth $\left\{y_{t}\right\}$, monthly UR $\left\{x_{t-2 / 3}, x_{t-1 / 3}, x_{t}\right\}$ and monthly EMP $\left\{z_{t-2 / 3}, z_{t-1 / 3}, z_{t}\right\}$

- Let $W_{t}=\left[x_{t-2 / 3}, z_{t-2 / 3}, x_{t-1 / 3}, z_{t-1 / 3}, x_{t}, z_{t}, y_{t}\right]^{\prime}$ 


\section{What is Blocking? An Example 2}

- Suppose 3 series: quarterly GDP growth $\left\{y_{t}\right\}$, monthly UR $\left\{x_{t-2 / 3}, x_{t-1 / 3}, x_{t}\right\}$ and monthly EMP $\left\{z_{t-2 / 3}, z_{t-1 / 3}, z_{t}\right\}$

- Let $W_{t}=\left[x_{t-2 / 3}, z_{t-2 / 3}, x_{t-1 / 3}, z_{t-1 / 3}, x_{t}, z_{t}, y_{t}\right]^{\prime}$

- EMP, UR are released on the first Friday

$$
A_{0}=\left(\begin{array}{lllllll}
a_{11} & a_{12} & 0 & 0 & 0 & 0 & 0 \\
a_{21} & a_{22} & 0 & 0 & 0 & 0 & 0 \\
a_{31} & a_{32} & a_{33} & a_{34} & 0 & 0 & 0 \\
a_{41} & a_{42} & a_{43} & a_{44} & 0 & 0 & 0 \\
a_{51} & a_{52} & a_{53} & a_{54} & a_{55} & a_{56} & 0 \\
a_{61} & a_{62} & a_{63} & a_{64} & a_{65} & a_{66} & 0 \\
a_{71} & a_{72} & a_{73} & a_{74} & a_{75} & a_{76} & a_{77}
\end{array}\right)
$$




\section{Real-time Data}

- Compiled from ALFRED (ArchivaL Federal Reserve Economic Data) and Haver Analytics

- We have monthly vintages from 1980:1 to 2013:7 (using the one staring at 1985:1) 


\section{Real-time Data}

- Compiled from ALFRED (ArchivaL Federal Reserve Economic Data) and Haver Analytics

- We have monthly vintages from 1980:1 to 2013:7 (using the one staring at 1985:1)

- Coverage for 1971:1-2013:6, monthly and quarterly

- Some series start later, e.g., PCE headline and core in 2000:7 which implies a changing model structure 


\section{Real-time Data}

- Compiled from ALFRED (ArchivaL Federal Reserve Economic Data) and Haver Analytics

- We have monthly vintages from 1980:1 to 2013:7 (using the one staring at 1985:1)

- Coverage for 1971:1-2013:6, monthly and quarterly

- Some series start later, e.g., PCE headline and core in 2000:7 which implies a changing model structure

- We have 24 data series: only one is quarterly

- Weekly and daily data aggregated to monthly - end of period, average 


\section{Real-time Data}

- Compiled from ALFRED (ArchivaL Federal Reserve Economic Data) and Haver Analytics

- We have monthly vintages from 1980:1 to 2013:7 (using the one staring at 1985:1)

- Coverage for 1971:1-2013:6, monthly and quarterly

- Some series start later, e.g., PCE headline and core in 2000:7 which implies a changing model structure

- We have 24 data series: only one is quarterly

- Weekly and daily data aggregated to monthly - end of period, average

- Data has been transformed to stationarity 


\section{Real-time Data (Cont.)}

\begin{tabular}{llll}
\hline \hline Name & Release Date & Publ. Lag & Vintage \\
\hline \hline & Group 1 & & \\
\hline ISM Manufacturing PMI (s.a.) & 1st business day & one month & 1997:03 \\
ISM Supplier Deliveries Index (s.a.) & 1st business day & one month & $2009: 11$ \\
ISM New Orders Index (s.a) & 1st business day & one month & $2009: 11$ \\
Civilian Unempl. Rate, 16+ (s.a.) & 1st Friday & one month & $1980: 01$ \\
Empl. on Nonfarm Payrolls: Total (s.a.) & 1st Friday & one month & $1980: 01$ \\
Avg Weekly Manufacturing Hours & 1st Friday & one month & $1980: 01$ \\
\hline & Group 2 & & \\
\hline Industrial Production & after 2 weeks & one month & $1980: 01$ \\
New Res. Constr./Housing Starts (s.a) & 12th workday & one month & $1980: 01$ \\
Phily Fed Bus. Outlook Survey (s.a.) $*$ & 3rd Thurs & curr. month & $1980: 01$ \\
CPI Headline (s.a.) & varying, mid-month & one month & $1980: 01$ \\
CPI Core (s.a.) & varying, mid-month & one month & 1996:12 \\
\hline \hline
\end{tabular}




\section{Real-time Data (Cont.)}

\begin{tabular}{|c|c|c|c|}
\hline Name & Release Date & Publ. Lag & Vintage \\
\hline \multicolumn{4}{|c|}{ Group 3} \\
\hline New (1-Family) Houses Sold (s.a.) & 17 th workday & one month & 1999:07 \\
\hline Consumer Sentiment Index (n.s.a) * & last Friday & curr. month & 1980:01 \\
\hline GDP Advance Estimate (s.a.) & last week of month & one month & 1980:01 \\
\hline \multicolumn{4}{|c|}{ Group 4} \\
\hline PCE Headline (s.a.) & day after GDP & one month & 2000:07 \\
\hline PCE Core (s.a.) & day after GDP & one month & 2000:07 \\
\hline Personal Income (s.a) & day after GDP & one month & 1980:01 \\
\hline \multicolumn{4}{|c|}{ Group 5} \\
\hline Initial Unempl Insurance Claims (s.a.) & last Thursday & one week & 2009:06 \\
\hline Federal Funds (Effective) Rate $*$ & last day & curr. month & 1980:01 \\
\hline Term Spread (10-Year - 3-Month) * & last day & curr. month & 1980:01 \\
\hline WTI Oil Price $*$ & last day & curr. month & 1980:01 \\
\hline S\&P 500 Stock Index * & last day & curr. month & 1980:01 \\
\hline Credit Spread (Baa - Aaa) $*$ & last day & curr. month & 1980:01 \\
\hline Trade Weighted Exch. Rate* & last day & curr. month & 1980:01 \\
\hline
\end{tabular}




\section{Timing assumptions}

- The goal is to take the timing assumptions of data releases (information flow) seriously

- Order the data based on release date not by reference date

\begin{tabular}{|clc|}
\hline & $g_{1}^{1}$ & some associated with \\
January, 2013 & $g_{2}^{1}$ & December, 2012 \\
GDP Advance Release & $g_{3}^{1}$ & January, 2013 \\
& $g_{4}^{1}$ & 4th quarter, 2012 \\
& $g_{5}^{1}$ & \\
\hline
\end{tabular}

$\Downarrow$

part of the information set in January, 2013 - balanced panel 


\section{Timing assumptions}

- Variables in each group are contemporaneously correlated

- Variables in each group respond contemporaneously to the group before (if exists), but not to the ones after 
Good luck! How Many Parameters are there to Estimate?

- More than one would want 


\section{Good luck! How Many Parameters are there to Estimate?}

- More than one would want

- Particularly for data spanning 1971:1-2013:4 42 years of monthly/quarterly data 


\section{Good luck! How Many Parameters are there to Estimate?}

- More than one would want

- Particularly for data spanning 1971:1-2013:4 42 years of monthly/quarterly data

- The hope is that with enough shrinkage we can control the excessive estimation risk

- Banbura, Giannone, and Reichlin (2010), De Mol, Giannone, and Reichlin (2008) 


\section{Estimation: Sims-Zha Shrinkage Prior}

Re-write the system as

$$
w_{t+h}^{\prime} B=x_{t}^{\prime} G+\epsilon_{t}^{\prime}
$$

Consider a prior of a following form:

$$
b_{i} \sim N\left(0, \bar{S}_{i}\right) \text { and } g_{i} \mid b_{i} \sim N\left(\bar{P}_{i} b_{i}, \bar{H}_{i}\right)
$$

such that $\bar{H}_{i j j}=\frac{\lambda_{0}^{2} \lambda_{1}^{2}}{\sigma_{j}^{2} p^{2 \lambda_{3}}}$ and $\bar{S}_{i_{j j}}$ are defined by $\frac{\lambda_{0}^{2}}{\sigma_{j}^{2}}$

- prior hierarchical in nature

\begin{tabular}{lll}
\hline \hline$\lambda_{0}$ & $?$ & controls the overall tightness of the beliefs \\
$\lambda_{1}$ & $?$ & tightens the prior around the mean \\
$\lambda_{3}$ & 1 & rate of contraction with an increase in lag length \\
$\lambda_{4}$ & 1 & controls the tightness of the constant \\
\hline
\end{tabular}




\section{Estimation: Algorithm}

Waggoner and Zha (2003):

$$
w_{t+h}^{\prime} B=x_{t}^{\prime} G+\epsilon_{t}^{\prime}
$$

Given the model and the restrictions

$$
\begin{aligned}
Q_{i} b_{i} & =0 \\
R_{i} g_{i} & =0
\end{aligned}
$$

one can find $U_{i}$ and $V_{i}$ such that

$$
\begin{aligned}
\psi_{i} & =U_{i} b_{i} \\
\phi_{i} & =V_{i} g_{i}
\end{aligned}
$$

The posterior distributions take the form

$$
\begin{aligned}
p\left(\psi_{1}, \ldots, \psi_{n} \mid x_{t}\right) & \propto\left|\operatorname{det}\left[U_{1} \psi_{1}|\ldots| U_{n} \psi_{n}\right]\right|^{T} \exp \left(-\frac{T}{2} \sum_{i=1}^{n} \psi_{i}^{\prime} S_{i}^{-1} \psi_{i}\right) \\
p\left(\phi_{i} \mid \psi_{i}, x_{t}\right) & =\varphi\left(P_{i} \psi_{i}, H_{i}\right) .
\end{aligned}
$$




\section{On the Prior}

- How to pick the hyperparameters?

- Use values from the literature - have not been optimized for the monthly/quarterly structure that we have in our setup.

- Consider hyperparameter selection mechanism - grid search

- Derive the marginal data density for our VAR (similar to Giannone, Lenza and Primiceri, 2015) 


\section{Unconditional Forecasting}

- Three states of our world: end of first, second, and third month of quarter

- In the second (third) month of the quarter we have one complete set of month one (and two) variables

- At the end of the first month of each quarter - January, April, July, October vintages - our quarterly information set is complete

- We estimate the VAR only when we have a full set of data, i.e. once a quarter

- We evaluate the forecasts using quarterly vintages, i.e. forecasts produced in January, February and March are all evaluated against the April vintage 


\section{Unconditional Forecasting}

The system is

$$
w_{t+h}^{\prime} B=x_{t}^{\prime} G+\epsilon_{t}^{\prime}
$$

Forecasts and forecast errors are

- At the end of the first month of quarter

$$
\hat{w}_{t+1 \mid t}^{\prime}=x_{t}^{\prime} G B^{-1}
$$

- At the end of the second month of each quarter

$$
\begin{aligned}
& \hat{\epsilon}_{t+1 / 3}=B^{\prime} i_{1 / 3}\left(w_{t+1 / 3}-i_{1 / 3}^{\prime} \hat{w}_{t+1}\right) \\
& \hat{w}_{t+1 \mid t+1 / 3}^{\prime}=\hat{w}_{t+1 \mid t}^{\prime}+\left[\hat{\epsilon}_{t+1 / 3} ; 0\right]^{\prime} B^{-1}
\end{aligned}
$$

- At the end of the third month of each quarter

$$
\begin{aligned}
& \hat{\epsilon}_{t+2 / 3}=B^{\prime} i_{2 / 3}\left(w_{t+2 / 3}-i_{2 / 3}^{\prime} \hat{w}_{t+1 \mid t+1 / 3}\right) \\
& \hat{w}_{t+1 \mid t+2 / 3}^{\prime}=\hat{w}_{t+1 \mid t+1 / 3}^{\prime}+\left[0 ; \hat{\epsilon}_{t+2 / 3} ; 0\right]^{\prime} B^{-1}
\end{aligned}
$$




\section{Performance: the Alternatives}

Quarterly models:

- "AR-Quarterly"

- Estimate monthly and quarterly ARs with January, April, July, October vintages

- For monthly variables construct up to three-step-ahead forecasts (with no new information)

- Compare the average monthly forecast to the average monthly realization

- "VAR-Quarterly"

- Average the monthly variables to a quarterly frequency

- "BVAR-Quarterly" - similar to "AR-Quarterly"

- No need for multi-step-ahead forecasting since the set-up generates it by construction 


\section{Performance: Results}

Mixed models:

- "AR-Mixed"

- Estimate monthly and quarterly ARs with January, April, July, October vintages

- For monthly variables construct three one-step-ahead forecasts with inter-quarter vintages

- Compare forecasts to the realizations in next quarterly vintage

- "BVAR-Mixed"

- Estimate the VARs with January, April, July, October vintages

- Construct forecasts with inter-quarter vintages

- Compare forecasts to the realizations in next quarterly vintage

- SPF (Survey of Professional Forecasters) 


\section{Performance: Results}

Evaluation is based on the mean of the forecast distribution which is consistent with quadratic loss (Gneiting, 2012)

Quarterly Models

\begin{tabular}{|l|c|c|c|c|}
\hline \hline & EMP & CPI & FFR & GDP \\
\hline \hline AR-Quarterly & 0.24 & 0.70 & 0.58 & 1.78 \\
VAR-Quarterly & 1.71 & 1.50 & 1.46 & 1.23 \\
BVAR-Quarterly & 1.91 & 1.53 & 1.26 & 0.99 \\
SPF & - & - & - & 0.74 \\
\hline \hline
\end{tabular}


Performance: the Alternatives

Mixed Models

\begin{tabular}{|l|c|c|c|c|}
\hline \hline & AR-Mixed & BVAR - M1 & BVAR - M2 & BVAR - M3 \\
\hline EMP-M1 & 0.46 & 1.18 & & \\
CPI-M1 & 1.08 & 1.09 & & \\
FFR-M1 & 0.86 & 1.03 & & \\
EMP-M2 & 0.49 & 1.26 & 1.14 & \\
CPI-M2 & 1.15 & 1.21 & 1.02 & \\
FFR-M2 & 0.84 & 1.17 & 1.61 & \\
EMP-M3 & 0.45 & 1.28 & 1.15 & 1.13 \\
CPI-M3 & 1.04 & 1.27 & 1.22 & 1.04 \\
FFR-M3 & 0.71 & 1.22 & 1.34 & 1.33 \\
GDP & 1.78 & 0.99 & 0.85 & 0.87 \\
\hline \hline
\end{tabular}


Performance: Forecasts

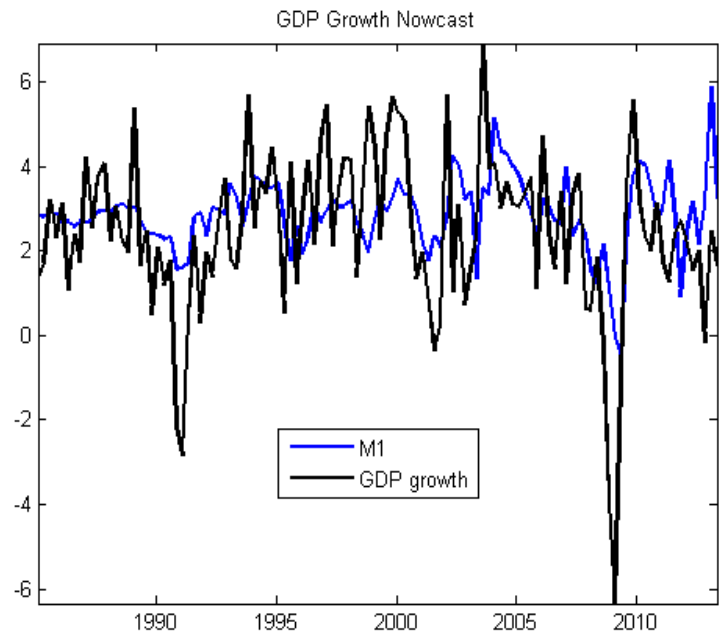


Performance: Forecasts

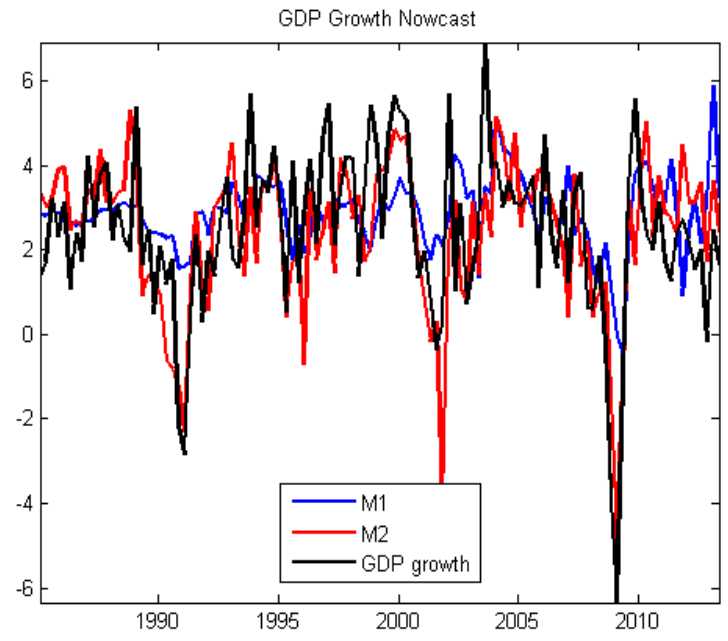


Performance: Forecasts

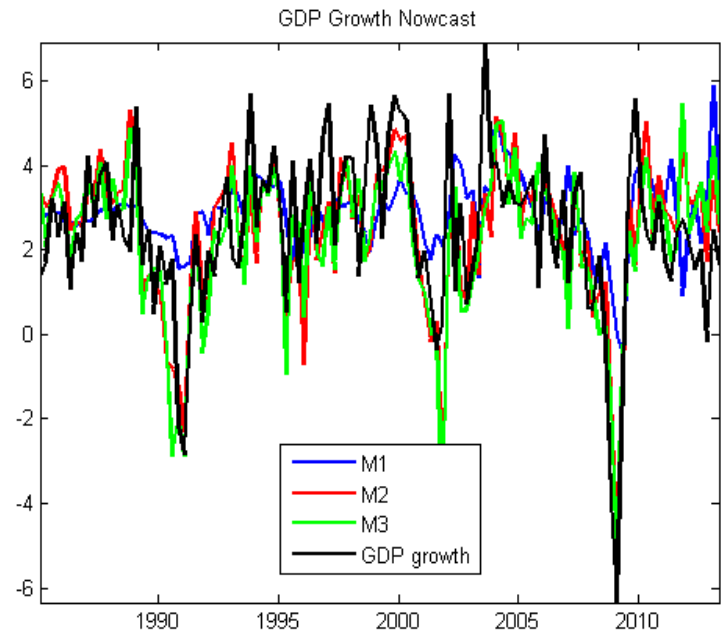


Performance: Forecasts

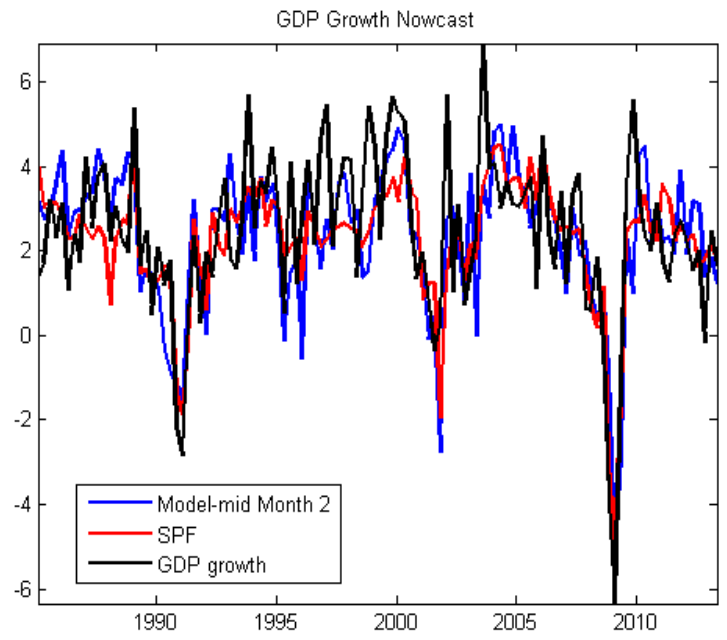




\section{Performance: Rolling RMSE}

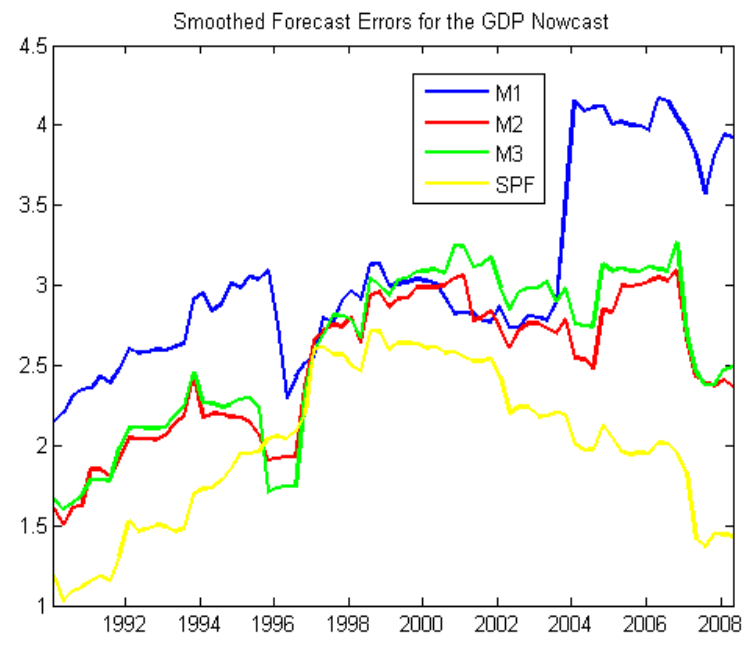




\section{Performance: Rolling RMSE}

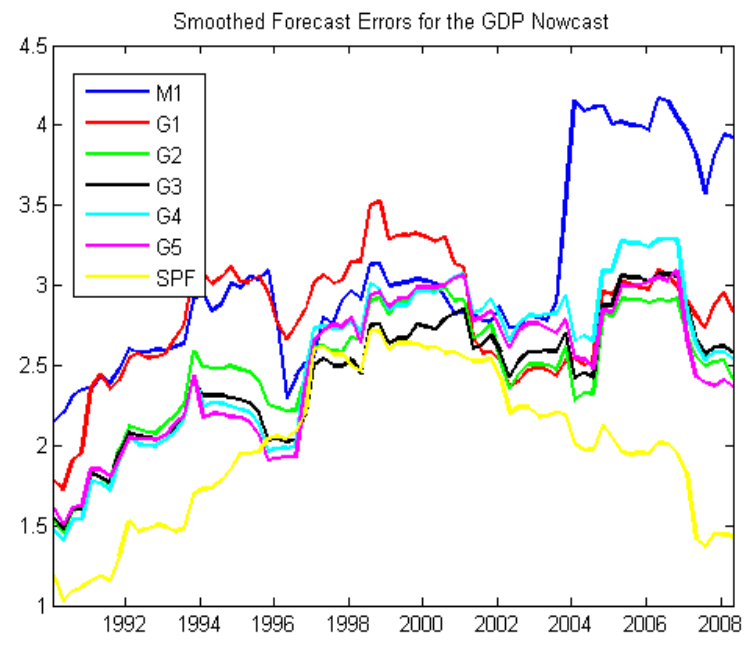




\section{Performance: Rolling RMSE}

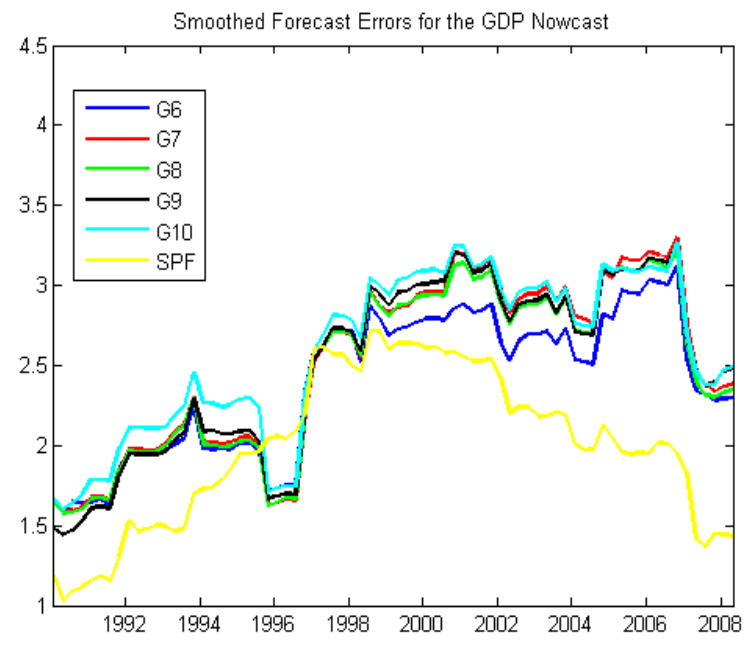




\section{Performance: Rolling Root Median Squared Error}

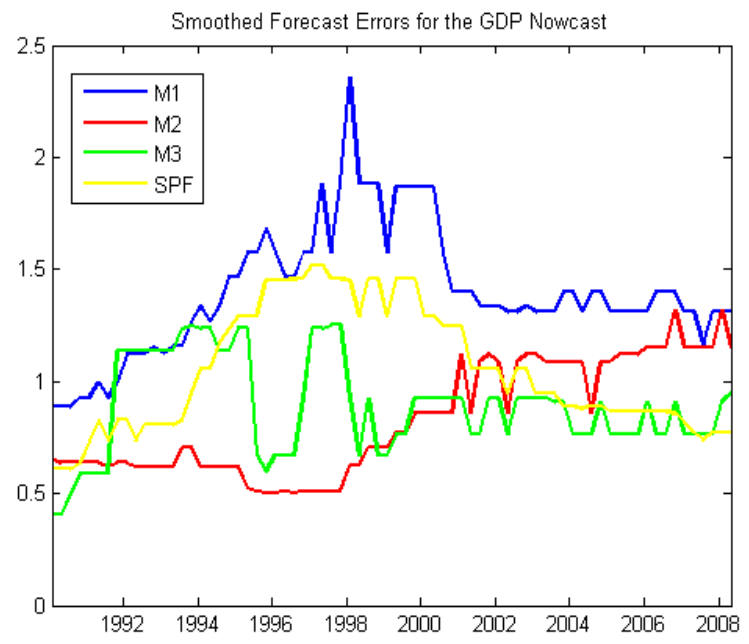




\section{Performance: Rolling Root Median Squared Error}

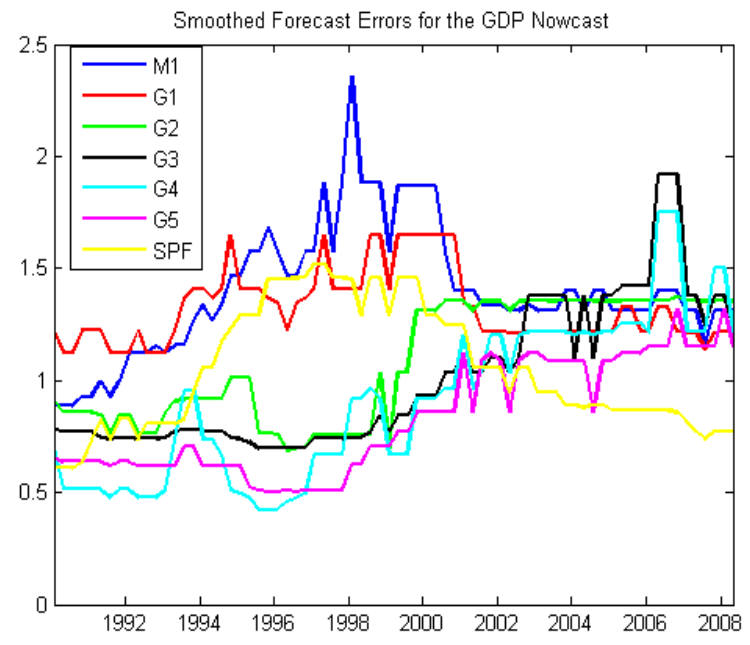




\section{Performance: Rolling Root Median Squared Error}

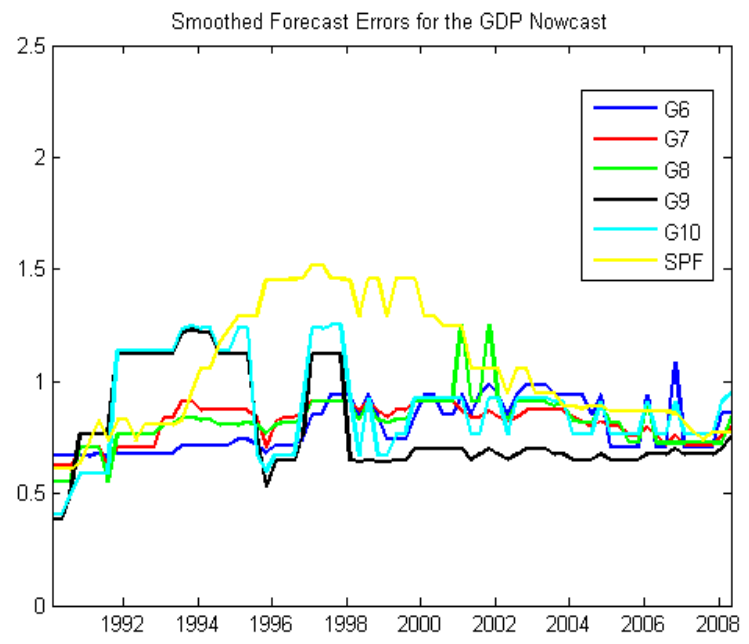




\section{Some Structural Analysis: Monetary Policy Shocks}

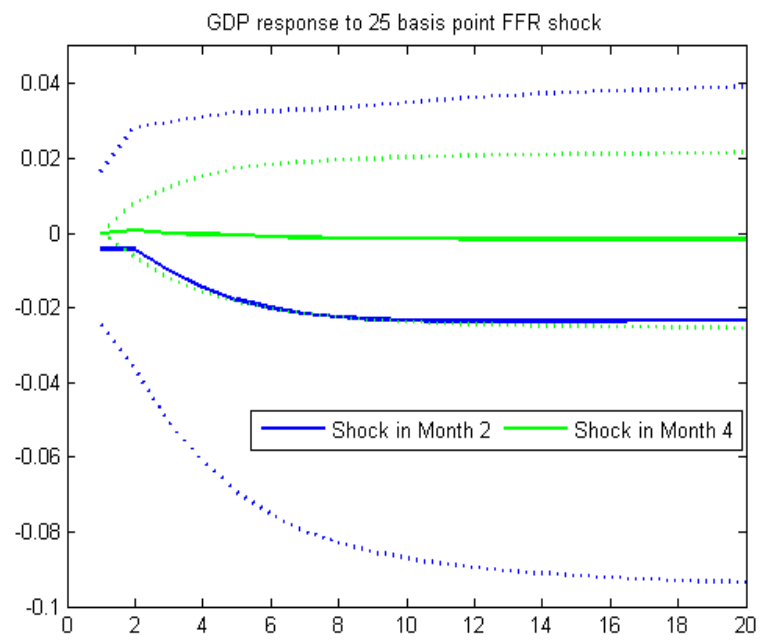




\section{Some Structural Analysis: Monetary Policy Shocks}

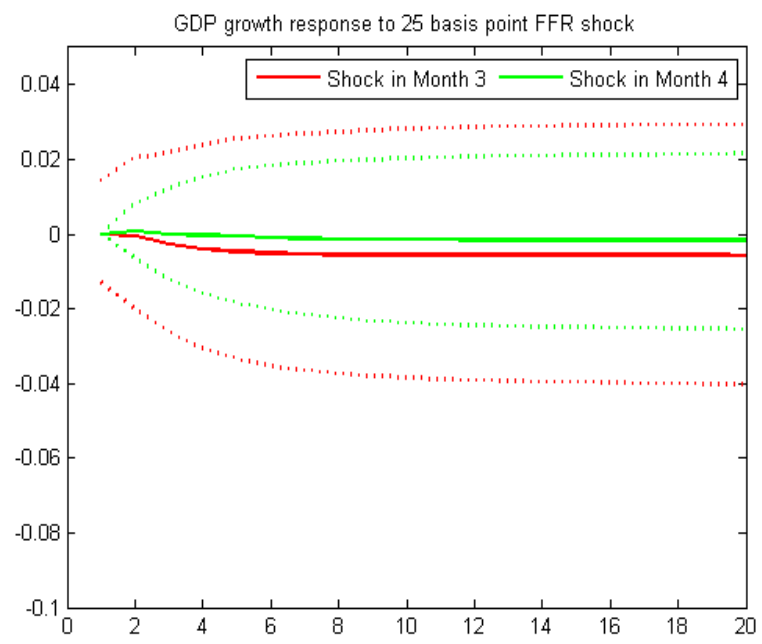




\section{Conclusions}

- We have an easy way to mix monthly and quarterly variables into a meaningful forecasting framework.

- Can be a viable alternative for providing high frequency updates.

- Can consider for "structural" analysis with interesting interpretations.

- Comments? Thank you! 